\title{
Perceived quality of life and physical activity in Brazilian older adults
}

\author{
Percepção da qualidade de vida e atividade física em idosos brasileiros
}

\author{
D.B. Porto, D.P. Guedes, R.A. Fernandes, F.F. Reichert
}

ARTIGO ORIGINAL | ORIGINAL ARTICLE The purpose of this study was to investigate the association between self-perceived quality of life and physical activity in Brazilian older adults. We investigated 199 individuals (117 men and 82 women) aged between 60 to 70 years old, employees of a public university. Physical activity was estimated by the short version of the International Physical Activity Questionnaire (IPAQ). Self-perceived quality of life was assessed using the World Health Organization Quality of Life (WHOQOL-Bref) questionnaire composed of four domains: physical, psychological, social relationship and environment. There was no difference in self-perceived quality of life between men and women. In contrast, quality of life was associated with physical activity even after adjustment for gender, schooling and income. The physical domain presented the strongest association with physical inactivity (Odds Ratio $=2.70,95 \% \mathrm{CI}$ $1.87-3.52)$. Only the environment domain evaluated by WHOQOL-Bref was not associated to physical inactivity. Among the older, improved self-perceived quality of life is positively associated to physical activity.

Keywords: quality of life, physical activity, aging, lifestyle

RESUMO

O objetivo deste estudo foi investigar a associação entre autopercepção da qualidade de vida e atividade física em idosos brasileiros. Foram investigados 199 indivíduos (117 homens e 82 mulheres) com idade entre 60 a 70 anos, funcionários de uma universidade pública. A atividade física foi estimada pela versão curta do Questionário Internacional de Atividade Física (IPAQ). A autopercepção da qualidade de vida foi avaliada utilizando o questionário World Health Organization Quality of Life (WHOQOLBref) composto por quatro domínios: físico, psicológico, relações sociais e meio ambiente. Não houve diferença na autopercepção da qualidade de vida entre homens e mulheres. Em contrapartida, a qualidade de vida foi associada com atividade física quando ajustada pelo sexo, escolaridade e renda. O domínio físico foi o que apresentou a associação mais elevada com a atividade física (Odds Ratio = 2.70, IC 95\% 1.87-3.52). Apenas o domínio meio ambiente avaliado pelo WHOQOL-Bref não foi associado com inatividade física. Em sujeitos idosos, a melhoria da autopercepção da qualidade de vida está significativamente associada à atividade física.

Palavras-chave: qualidade de vida, atividade física, envelhecimento, estilo de vida

Submetido: 15.12.2010 | Aceite: 22.01.2011

Denilson Braga Porto e Dartagnan Pinto Guedes. Centro de Educação Física e Esporte, Universidade Estadual de Londrina, Londrina-PR, Brasil.

Rômulo Araújo Fernandes. Departamento de Educação Física, Universidade Estadual Paulista, Rio Claro/SP, Brasil.

Felipe Fossati Reichert. Escola Superior de Educação Física, Universidade Federal de Pelotas, Pelotas/RS, Brasil.

Endereço para correspondência: Denilson Braga Porto, Centro de Educação Física e Esporte, Campus Universitário - Rodovia Celso Garcia Cid, PR 445, Km 380, CEP: 86051-980 Londrina, Paraná, Brasil

E-mail: dbporto@hotmail.com 
Despite the worldwide increase in life expectancy, the negative impact of the biological ageing process may affect, directly or indirectly, the individual perception of quality of life in advanced ages. Therefore, in addition to the traditional information provided by morbidity and mortality indices, the evaluation of individual and subjective indicators of quality of life among older adults has been the focus of many public health policies. This is largely related to the concept that a favorable self-perception of quality of life may help minimizing the limitations resulting from the ageing process (Elavsky et al., 2005).

Evidence in the literature suggests that physical activity decreases the risk of several chronic degenerative disorders (Babic et al., 2004; Bassuk \& Manson, 2005; Paffenbarger, 2000; Pitanga, Almeida, Freitas, Pitanga, \& Beck, 2010), increases the capacity for physical labor (Aidar et al., 2006; Amara et al., 2000; Mao, Pan, Wen, \& Johnson, 2003; Puggaard, Larsen, Stovring, \& Jeune, 2000), and wellbeing (McAuley, Elavsky, Jerome, Konopack, \& Marquez, 2005; Netz, Wu, Becker, \& Tenenbaum, 2005), improves self-esteem and self-efficacy (McAuley, Blissmer, Katula, Duncan, \& Mihalko, 2000) and reduces eventual problems associated to the lack of physical autonomy (Vita, Terry, Hubert, \& Fries, 1998). Most studies were carried out in high-income countries, and whether their findings can be extrapolated to other settings remains to be determined. Another issue to be investigated is whether the magnitude of the association between physical activity and health outcomes observed in rich countries is similar in poorer settings.

Public health policies have sought to encourage a physically active lifestyle, as an attempt to prevent potential outcomes that may affect quality of life in all age groups. According to Lee, Paffenbarger e Hennekens (1997), this is especially true for older ages, when risks associated with insufficient and inadequate physical activity are increased, affecting working years of life.
However, data supporting the positive association between a physically active lifestyle and indicators related to quality of life may be hindered by differences in the nature and specifications of the instruments to measure physical activity and/or quality of life. Hence, since the late 1990's, groups of specialists have focused on the elaboration and dissemination of internationally validated and standardized instruments to investigate physical activity and quality of life.

Among the available instruments there is the International Physical Activity Questionnaire - IPAQ (Craig et al., 2003) and the World Health Organization Quality of Life WHOQOL - questionnaire (WHOQOL Group, 1998) that aims at investigating physical activity and quality of life, respectively. The main characteristic of both instruments is to consider cultural and linguistic equivalency in international intra and inter-population comparisons.

The aim of the present study was to investigate the association between self-perceived quality of life and physical activity in Brazilian older adults using the above mentioned instruments.

\section{Sample}

METHOD

The study participants were all employees aged between 60 and 70 years of the State University of Londrina. Londrina has $\sim 500000$ inhabitants and is the third most populous city of the South of Brazil.

The universe of eligible subjects (382 subjects) was identified through a registry containing identification, date of birth, work sector, and professional position including all the institution's employees. The sample was randomly selected stratified by sex and work sector of the employees. Sampled individuals were contacted and, prior to the instrument administration, agreed and signed an informed consent form.

The study protocol was approved by the Research Ethics Committee of the Universidade 
Estadual de Maringá and conducted according to the standards of the Helsinki Declaration.

\section{Instruments}

\section{Physical activity}

Information regarding physical activity was obtained using the short version of the IPAQ, based on a 7-day recall period (Craig et al., 2003). The IPAQ was developed to collect information on the frequency (days/week) and duration (minutes/day) of walking and other moderate and vigorous physical activities, in addition to the daily time (minutes/day) spent sitting. The IPAQ investigates all domains of physical activity (i.e. leisure-time or exercises, occupation, commuting or household chore activities).

Physical inactivity was defined as less than 150 minutes/week of moderate to vigorous of physical activities. This classification is in accordance with current guidelines for physical activity (Haskell et al., 2007).

\section{Quality of life}

To assess self-perceived quality of life, the Portuguese version of the WHOQOL-Bref was used. This instrument comprises 24 items related to four domains: physical, psychological, social relationships, and environment. It also includes two items that were not included in the analysis model, related to the global perception of quality of life and health (Fleck et al., 2000). The information presented here refer to the 15 days before the interview, and each domain was analyzed apart by grouping responses according to a specific mathematical model based on a crude score (4-20), in which higher scores correspond to better self-perceived quality of life. We further dichotomized quality of life at the mean score of each domain to classify individuals with lower (below the mean) perception of quality of life for specific analyses.

It is important to highlight that in the present study the WHOQOL-Old model was not used because it was not available as the time of data collection. Furthermore, a study using the
WHOQL-Old found the psychometric characteristics in the Brazilian population to be inconsistent, requiring further investigations (Fleck, Chachamovich, \& Trentini, 2006). In contrast, the WHOQOL-Bref has been shown to be valid and reliable among Brazilian older (Chachamovich, Trentini, \& Fleck, 2007).

\section{Procedures}

Both instruments were administered individually, by a single researcher, at the subject's place of work and during work hours, between March and June of 2006. Subjects were handed the questionnaires along with instructions and recommendations regarding their completion. There was no time limit for completing the questionnaires. The researcher in charge of data collection was allowed to explain the questionnaire if necessary. Besides the application of the IPAQ and the WHOQOL-Bref, socioeconomic information was collected (years of formal education; monthly income (collected in $\mathrm{R} \$$ and then converted into $\mathrm{U} \$$ ) and job classification (professor or non-professor).

\section{Statistical Analysis}

Continuous variables presented normal distribution according to the Kolmogorov-Smirnov test with significance level at $5 \%$. Scores of perceived quality of life were analyzed using means \pm standard deviations and, afterwards, Student's t test was used to detect possible differences between genders. The categorical variables (schooling, income, job classification and physical activity) were analyzed using the Chi-Square $\left(\chi^{2}\right)$ test. We further explored the association between each domain of self-perceived quality of life (physical, psychological, social relationships, and environment) with physical inactivity. Thereby, each domain of quality of life was categorized into tertiles and compared with the physical activity level.

The odds ratios (OR) were measured by binary logistic regression. In the multivariable model, the domains of quality of life were included as independent variables and physical activity as dependent variable. All statistical 
analyses were carried out using the Statistical Package for the Social Sciences (SPSS), version 17.0.

\section{RESULTS}

Two hundred individuals were sampled to take part in the study and only one refused to participate. Table 1 describes the sample in terms of schooling, income, job classification and physical activity. Most participants were men (58.8\%), and non-professor (60.8\%). Physical inactivity was observed in approximately one quarter of the sample. There was no significant association between gender and schooling, income, job classification and physical inactivity.
Table 2 presents the mean scores obtained for each WHOQOL-Bref domain in men and women separately. In both genders, the median scores slightly varied (between 14.4 and 16.5). There were no statistical differences between mean scores for men and women in any of the four quality of life domains, except for psychological domain, in which men presented higher scores.

Table 3 presents the association between schooling, income and job classification with physical activity and self-perceived quality of life, controlled for gender. Physical activity was not associated with any of the exposures. In contrast, subjects with lower schooling, lower income and non professor were more likely to

Table 1

Characteristics of the sample in terms of schooling, income, job classification and physical activity level

\begin{tabular}{|c|c|c|c|c|}
\hline & $\begin{array}{c}\text { Women }(n=82) \\
\%\end{array}$ & $\begin{array}{c}\text { Men }(n=117) \\
\%\end{array}$ & $\chi^{2}$ & $p$ \\
\hline \multicolumn{5}{|l|}{ Schooling } \\
\hline$\leq 8$ years & 30.5 & 41.0 & \multirow{3}{*}{0.045} & \multirow{3}{*}{.832} \\
\hline $9-11$ years & 30.5 & 12.8 & & \\
\hline$\geq 12$ years & 39.0 & 46.2 & & \\
\hline \multicolumn{5}{|l|}{ Monthly Income } \\
\hline$<500$ US dollars & 40.2 & 36.8 & \multirow{3}{*}{1.985} & \multirow{3}{*}{.159} \\
\hline $500-1000$ US \$ & 34.2 & 28.2 & & \\
\hline$>1000$ US $\$$ & 25.6 & 35.0 & & \\
\hline \multicolumn{5}{|l|}{ Job Classification } \\
\hline Professor & 34.1 & 42.7 & \multirow{2}{*}{1.154} & \multirow{2}{*}{.283} \\
\hline Non-Professor & 65.9 & 57.3 & & \\
\hline \multicolumn{5}{|l|}{ Physical activity } \\
\hline$<150 \mathrm{~min} / \mathrm{wk}$ & 24.4 & 23.9 & \multirow{2}{*}{1.493} & \multirow{2}{*}{.222} \\
\hline$\geq 150 \mathrm{~min} / \mathrm{wk}$ & 75.6 & 76.1 & & \\
\hline
\end{tabular}

Table 2

Mean, standard deviation, and $t$ statistic for each domain of self-perceived quality of life score

\begin{tabular}{lcccc}
\hline & Women $(n=82)$ & Men $(n=117)$ & $t$ & $p$ \\
\hline Physical domain & $15.9 \pm 2.1$ & $16.1 \pm 2.2$ & -0.90 & .368 \\
Psychological domain & $16.1 \pm 1.6$ & $16.6 \pm 1.5$ & -1.97 & .049 \\
Social relationship domain & $15.8 \pm 2.4$ & $16.2 \pm 1.9$ & -1.51 & .131 \\
Environment domain & $14.4 \pm 1.8$ & $14.9 \pm 1.8$ & -1.81 & .070 \\
\hline
\end{tabular}


present poorer self-perceived quality of life. In the present sample, subjects reporting $\leq 8$ years of schooling showed between $32 \%$ (environment domain: $\mathrm{OR}=1.32,95 \%$ CI $1.05-$ 1.69) and $61 \%$ (physical domain: $\mathrm{OR}=1.61$, 95\% CI 1.34-1.95) greater chance of presenting lower self perceived quality of life when compared to their peers with 12 years of schooling. With respect to income, subjects who reported $<500$ US Dollars/month presented between $38 \%$ (social relationships domain: $\mathrm{OR}=1.38,95 \%$ CI $1.01-1.82)$ and $64 \%$ (psychological domain: $\mathrm{OR}=1.64,95 \% \mathrm{CI}$ 1.31-1.85) greater chance of showing lower self-perceived quality of life than peers earning $>1000$ US Dollars/month. Non-professor subjects demonstrated between 29\% (social relationship domain: $\mathrm{OR}=1.29,95 \% \mathrm{CI}$ 1.03-1.61) and 35\% (psychological domain: $\mathrm{OR}=1.35 \%, 95 \%$ CI 1.06-1.67) more chance to present a lower self-perceived quality of life compared to professors.
Table 4 presents the multivariable analyses for the association between self-perceived quality of life and physical inactivity. Subjects with lower scores in self-perceived quality of life were more likely to be inactive than subjects with higher scores for self-perceived quality of life. The strongest association was observed for the physical domain (OR $=2.70$, $95 \%$ CI $1.87-3.52)$, whereas only the environment domain $(\mathrm{OR}=1.89,95 \% \mathrm{CI}$ 0.96-3.25) did not presented a significant association with physical inactivity.

\section{DISCUSSION}

This study presents data about physical activity and self-perceived quality of life from a sample of Brazilian older adults evaluated with the short version of the IPAQ and WHOQOLBref. The main finding of the study was that higher levels of habitual physical activity were associated with higher self-perceived quality of live scores.

Table 3

Association of schooling, income and job classification with the outcomes physical inactivity and self-perceived quality of life (Values are Odds Ratios (95\% CI) adjusted for gender)

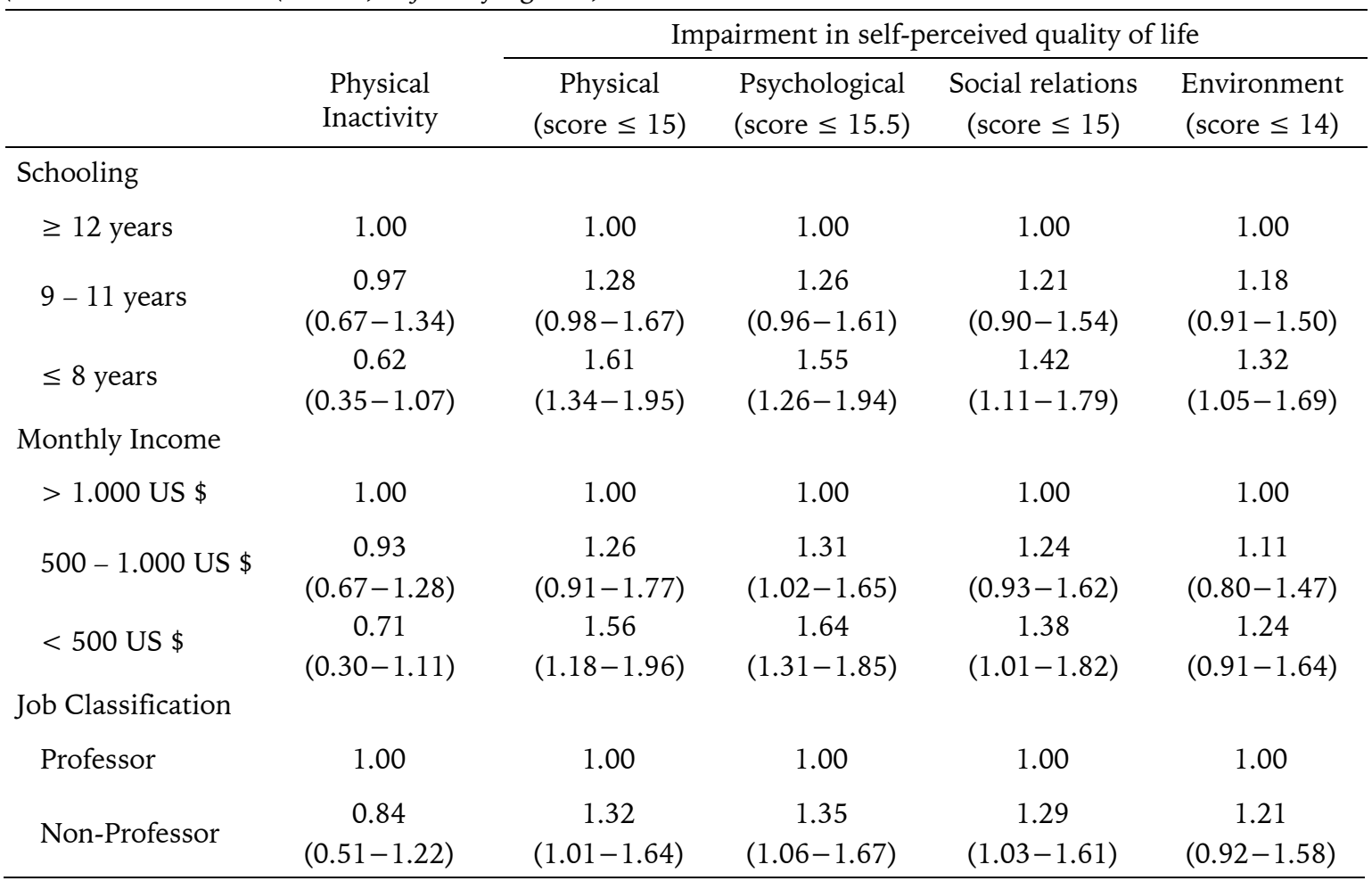


Table 4

Multivariable analyses for the association between physical inactivity and quality of life (Values are Odds Ratios (95\% CI) controlling for gender, schooling, and income)

\begin{tabular}{lc}
\hline Domains $($ Scores $)$ & Physical inactivity \\
\hline Physical & 1.00 \\
$3^{\text {rd }}$ tercile $(\geq 17)$ & $1.76(0.83-2.67)$ \\
$2^{\text {nd }}$ tercile $(15-17)$ & $2.70(1.87-3.52)$ \\
$1^{\text {st }}$ tercile $(<15)$ & 1.00 \\
Psychological & $1.68(1.17-2.76)$ \\
$3^{\text {rd }}$ tercile $(\geq 17.5)$ & $2.45(1.45-3.11)$ \\
$2^{\text {nd }}$ tercile $(15.5-17.5)$ & 1.00 \\
$1^{\text {st }}$ tercile $(<15.5)$ & $1.57(0.85-2.68)$ \\
Social relationships & \\
$3^{\text {rd }}$ tercile $(\geq 17)$ & $2.14(1.19-3.26)$ \\
$2^{\text {nd }}$ tercile $(15-17)$ & 1.00 \\
$1^{\text {st }}$ tercile $(<15)$ & $1.53(0.63-2.65)$ \\
Environment & $1.89(0.96-3.25)$ \\
$3^{\text {rd }}$ tercile $(\geq 15.5)$ & \\
$2^{\text {nd }}$ tercile $(14-15.5)$ & \\
$1^{\text {st }}$ tercile $(<14)$ &
\end{tabular}

The relationship between physical activity and self-perceived quality of life in different population groups has been studied (Aidar et al., 2006; Bernstein, Costanza, \& Morabia, 2001; Gómez, Duperly, Lucumi, Gómez, \& Venegas, 2005; Matsudo et al., 2002; Rütten \& Abu-Omar, 2004; Sarkisian, Prohaska, Wong, Hirsch, \& Mangione, 2005). However, none of these studies used internationally recognized instruments to measure both physical activity and quality of life. This drawback has hindered comparison across studies and limited the confidence to generalize their findings. Thus, we believe our data are important and provide reliable estimates of the association between physical activity and self-perceived quality of life.

The physical activity level found in this study is in agreement with other studies that applied the IPAQ (Gómez et al., 2005; Matsudo et al., 2002; Rütten \& Abu-Omar, 2004). Our results indicate that, after the age of 60 years, despite the slightly greater proportion of women classified as inactive, both gen- ders present similar behavior in terms of physical activity level. Our data indicate a lower proportion of inactivity than those reported in European (Rütten \& Abu-Omar, 2004), South American (Gómez et al., 2005), and other Brazilian studies (Matsudo et al., 2002). The reason for these differences is likely to be related to the characteristics of the participants. In the present study, the sample was composed by employees of a public university. The activities performed by these subjects include teaching, administration, maintenance, gardening, security, etc. Some of the tasks demand occupational physical activity and, as the short version of the IPAQ evaluates all-domains of physical activity, a lower proportion of inactivity is expected. Furthermore, the sample is somehow biased when compared to the Brazilian population as a whole, since it oversampled individuals from higher socioeconomic status than the average Brazilian population.

The evaluation of self-perceived quality of life using WHOQOL-Bref showed similar patterns of mean scores across the four domains and among men and women, indicating an important reciprocal influence among domains. These data are in agreement with those obtained in the original multicenter study that evaluated the instrument (WHOQOL Group, 1998). Nonetheless, it is important to analyze each domain of quality of life separately, because quality of life is considered a multidimensional construct (WHOQOL Group, 1998).

Other studies with elderly (60 to 90 years) evaluated the contribution of physical, psychological, social and environmental domains on the overall quality of life. The results indicate that the relative contribution of the four domains on global quality of life was approximately $36 \%$, with larger participation of the physical domain (28\%). The results also revealed that the different domains have limited participation on the explanatory capacity of the global quality of life scores. Therefore, data must be interpreted separately when the analy- 
sis of life quality in older subjects is the outcome (Pereira et al., 2006).

The mean scores for the dimensions of quality life found in this study are similar to those found in a sample of employees from the Federal University of Rio Grande do Sul (Brazil), except for the physical domain (Fleck et al., 2000). The lower score found for the physical domain in the present study may be due to differences in the age of subjects included in the two studies. In our study, subjects were 60 years and older, while the mean age among subjects from the Federal University of Rio Grande do Sul was 45 years.

Self-perceived quality of life is affected by organic, social, cognitive, and mental factors. Thus, it is highly dependent on the environment of the individual (Rejeski, Brawley, \& Shumaker, 1996). The advanced age of the subjects evaluated in the present study may have had greater negative effect on the physical domain of self-perceived quality of life. In contrast, this effect can be minimized when physical activity is increased. An experimental study carried out by Aidar et al. (2006) showed significant improvements on indicators of quality of life and $\mathrm{VO}_{2} \max$ in the subjects that underwent a physical activity program. Such an association was not observed in the control group.

An important contribution of the present study is the evaluation of associations. Lower perceived quality of life was associated with lower schooling, income and job classification whereas no association was found for physical activity. The physical and the psychological domains showed the strongest association with these three indicators. In the present study, schooling $\leq 8$ years or earnings $<500$ US dollars/month or the performance of a nonteacher function increased the odds of lower scores in the evaluation of self-perceived quality of life by $32-64 \%$, respectively. The nonsignificant association between physical activity and schooling and income was also observed in other studies using the IPAQ and employing binary logistic regression (Gómez et al., 2005; Rütten \& Abu-Omar, 2004). How- ever, when using instruments other than the IPAQ (Bernstein et al., 2001), or other types of statistical analysis (Matsudo et al., 2002), physical activity was not always unrelated to schooling and income.

The association between physical activity and mental health has been previously studied. Based on a similar criteria to classify individuals' physical activity levels, a study with Portuguese elderly ( $n=168$, mean age $=72$ years) found that $41.1 \%$ were considered physically inactive. In addition, when physical activity participation was increased, higher levels of life satisfaction, self-esteem and personal growth were verified, being this effect superior in the elderly people who practiced at least 30 min/day of moderate-to-vigorous physical activities on five or more days in a week (Fernandes, Vasconcelos-Raposo, Pereira, Ramalho, \& Oliveira, 2009).

Original aspects of the present study include the assessment of the relationship between quality of life and physical activity among subjects aged 60-70 years, using the IPAQ and WHOQOL-Bref, respectively. Subjects with lower scores in self-perceived quality of life were more likely to be inactive than subjects with higher scores for self-perceived quality of life. Certain limitations should be considered when interpreting the results of the present study. First, although the psychometric indicators of the IPAQ fulfill the proposed acceptance criteria (Craig et al., 2003) it is still a subjective measure and its accuracy depends on the respondent. Further studies could use objective measures such as accelerometers to confirm our associations. Second, in light of the reports provided by the subjects of the present study, we found that self-perceived quality of life reflects individual responses, which depend exclusively on the subject's attitude toward different daily life situations and above all how he/she perceives the older age. Thus, considering that the study sample was composed of a universe of subjects with highly diverse life experiences, ranging from university teachers with post-graduate education to 
employees whose function requires minimal schooling, one cannot discard the possibility of bias in the subjects' interpretation of the questions included in WHOQOL-Bref. Moreover, because the sample included only employees of a given university the generalization of our findings shall be made with prudence.

In conclusion, our results suggest that improved self-perceived quality of life is significantly associated to physical activity among older adults. Despite the methodological difficulties inherent to studies aimed to investigate this issue, an improved understanding of the relationship between the physical activity and quality of life is important to formulate recommendations regarding modifications in lifestyle, mainly among those that have not been affected by disabling diseases and that are physically independent.

\section{Acknowledgements:}

The authors extend special thanks to staff of the State University of Londrina, Paraná, Brazil, for valuable help in conducting this study, and all study participants for their cooperation.

\section{Conflicts of Interest:}

Nothing to declare.

\section{Funding Sources:}

Nothing to declare.

\section{REFERÊNCIAS}

Aidar, F. J., Carneiro, A., Silva, A., Reis, V., Novaes, G. S., \& Pains, R. (2006). A prática de atividades físicas e a relação da qualidade de vida com o $\mathrm{VO}_{2}$ máx. predito. Motricidade, 2 (3), 167-177.

Amara, C. E., Koval, J. J., Johnson, P. J., Paterson, D. H., Winter, E., \& Cunningham, D. A. (2000). Modelling the influence of fat-free mass and physical activity on the decline in maximal oxygen uptake with age in older humans. Experimental Physiology, 85(6), 877-886.

Babic, Z., Deskin, M., Muacevic-Katanec, D., Erdeljic, V., Misigoj-Durakovic, M., \& Metelko, Z. (2004). Estimation of physical activity by different questionnaires in overweight subjects and patients with Type 2 diabetes mellitus: Relationship with anthropometric and meta- bolic variables. Diabetes, Nutrition \& Metabolism, 17(5), 280-289.

Bassuk, S. S., \& Manson, J. E. (2005). Epidemiological evidence for the role of physical activity in reducing risk of type 2 diabetes and cardio-vascular disease. Journal of Applied Physiology, 99, 1193-1204.

Bernstein, M. S., Costanza, M. C., \& Morabia, A. (2001). Physical activity of urban adults: A general population survey in Geneva. Sozial und Präventivmedizin, 46(1), 49-59. doi: 10.1007/BF 01318798

Chachamovich, E., Trentini, C., \& Fleck, M. P. (2007). Assessment of the psychometric performance of the WHOQOL-BREF instrument in a sample of Brazilian older adults. International Psychogeriatrics, 19(4), 635-646. doi: 10.10 17/S1041610206003619

Craig, C. L., Marshall, A. L., Sjostrom, M., Bauman, A. E., Booth, M. L., Ainsworth, B. E. ... Oja, P. (2003). International Physical Activity Questionnaire: 12-Country Reliability and Validity. Medicine \& Science in Sports \& Exercise, 35(8), 1381-1395. doi: 10.1249/01.MSS.0000078924. 61453.FB

Elavsky, S., McAuley, E., Motl, R. W., Konopack, J. F., Marquez, D. X., Hu, L. ... Diener, E. (2005). Physical activity enhances long-term quality of life in older adults: Efficacy, esteem, and affective influences. Annals of Behavioral Medicine, 30(2), 138-145. doi: 10.1207/s15324796abm30 $02 \_6$

Fernandes, H. M., Vasconcelos-Raposo, J., Pereira, E., Ramalho, J., \& Oliveira, S. (2009). A influência da actividade física na saúde mental positiva de idosos. Motricidade, 5(1), 33-50.

Fleck, M., Chachamovich, E., \& Trentini, C. (2006). Development and validation of the Portuguese version of the WHOQOL-OLD module. Revista de Saúde Pública, 40(5), 785-791.

Fleck, M., Louzada, S., Xavier, M., Chachamovich, E., Vieira, G., Santos, L., \& Pinzon, V. (2000). Aplicação da versão em português do instrumento abreviado de avaliação da qualidade de vida "WHOQOL-Bref". Revista de Saúde Pública, 34(2), 178-183. doi: doi.org/10.1590/S 003489102000000200012

Gómez, L. F., Duperly, J., Lucumi, D. I., Gómez, R., \& Venegas, A. S. (2005). Nível de actividad física global en la población adulta de Bogotá (Colômbia): Prevalência y factores asociados. Gaceta Sanitaria, 19(3), 206-213. 
Haskell, W. L., Lee, I. M., Pate, R. R., Powell, K. E., Blair, S. N., Franklin, B. A., ... Bauman, A. (2007). Physical activity and public health: Updated recommendation for adults from the American College of Sports Medicine and the American Heart Association. Circulation, 116(9), 1081-1093. doi: 10.1161/CIRCULATI ONAHA.107.185649

Lee, I. M., Paffenbarger, R. S., \& Hennekens, C. H. (1997). Physical activity, physical fitness and longevity. Aging (Milano), 9(1/2), 2-11.

Mao, Y., Pan, S., Wen, S., \& Johnson, K. (2003). Physical activity and the risk of lung cancer in Canada. American Journal of Epidemiology, 158(6), 564-575. doi: 10.1093/aje/kwg186

Matsudo, S. M., Matsudo, V., Araújo, T., Andrade, D., Andrade, E., Oliveira, L., \& Braggion, G. (2002). Nível da atividade física da população do Estado de São Paulo: Análise de acordo com o gênero, idade, nível socioeconômico, distribuição geográfica e de conhecimento. Revista Brasileira de Ciência E Movimento, 10(4), 41-50.

McAuley, E., Blissmer, B., Katula, J., Duncan, T. E., \& Mihalko, S. L. (2000). Physical activity, selfesteem, and self-efficacy relationships in older adults: A randomized controlled trial. Annals of Behavioral Medicine, 22(2), 131-139. doi: 10.100 7/BF02895777

McAuley, E., Elavsky, S., Jerome, G. J., Konopack, J. F., \& Marquez, D. X. (2005). Physical activityrelated well-being in older adults: Social cognitive influences. Psychology and Aging, 20(2), 295302. doi: 10.1037/0882-7974.20.2.295

Netz, Y., Wu, M. J., Becker, B. J., \& Tenenbaum, G. (2005). Physical activity and psychological well-being in advanced age: A meta-analysis of intervention studies. Psychology and Aging, 20(2), 272-284. doi: 10.1037/0882-7974.20.2. 272
Paffenbarger, R. (2000). Physical exercise to reduce cardiovascular disease risk. The Proceedings of the Nutrition Society, 59(3), 421-422.

Pereira, R. J., Cotta, R. M., Franceschini, S. C., Ribeiro, R. C., Sampaio, R. F., Priore, S. E., \& Cecon, P. R. (2006). Contribuição dos domínios físico, social, psicológico e ambiental para a qualidade de vida global de idosos. Revista de Psiquiatria do Rio Grande do Sul, 28(1), 27-38. doi: 10.1590/S0101-81082006000100005

Pitanga, F. J., Almeida, L. A., Freitas, M., Pitanga, C. P., \& Beck, C. C. (2010). Padrões de atividade física em diferentes domínios e ausência de diabetes em adultos. Motricidade, 6(1), 5-17.

Puggaard, L., Larsen, J. B., Stovring, H., \& Jeune, B. (2000). Maximal oxygen uptake, muscle strength and walking speed in 85-year-old women: Effects of increased physical activity. Aging (Milano), 12(3), 180-189.

Rejeski, W. J., Brawley, L. R., \& Shumaker, A. S. (1996). Physical activity and health-related quality of life. Exercise and Sport Sciences Reviews, 24(1), 71-108.

Rütten, A., \& Abu-Omar, K. (2004). Prevalence of physical activity in the European Union. Sozial und Präventivmedizin, 49(4), 281-289. doi: 10.10 07/s00038-004-3100-4

Sarkisian, C. A., Prohaska, T. R., Wong, M. D., Hirsch, S., \& Mangione, C. M. (2005). The relationship between expectations for aging and physical activity among older adults. Journal of General Internal Medicine, 20(10), 911-915. doi: 10.1111/j.1525-1497.2005.0204.x

Vita, A. J., Terry, R. B., Hubert, H. B., \& Fries, J. F. (1998). Aging, health risks, and cumulative disability. The New England Journal of Medicine, 338(15), 1035-1041.

WHOQOL Group (1998). Development of World Health Organization WHOQOL-Bref Quality of Life Assessment. Psychological Medicine, 28(3), 551-558.

(c) EY-Nc Todo o conteúdo da revista Motricidade está licenciado sob a Creative Commons, exceto quando especificado em contrário e nos conteúdos retirados de outras fontes bibliográficas. 